\title{
Hepatitis $E$ is more common than hepatitis $A$ among returning travellers presenting to tertiary care
}

\author{
Catherine Cosgrove ${ }^{1}$, Margaret Armstrong ${ }^{1}$, Mike Kidd ${ }^{2}$, Michael Brown ${ }^{1}$, Tom Doherty ${ }^{1}$ \\ ${ }^{1}$ Hospital for Tropical Diseases, London, UK \\ ${ }^{2}$ The Department of Virology, University College Hospitals London, London, UK \\ Email: ccosgrov@sgul.ac.uk
}

Received 15 August 2013; revised 25 September 2013; accepted 4 October 2013

Copyright (c) 2013 Catherine Cosgrove et al. This is an open access article distributed under the Creative Commons Attribution License, which permits unrestricted use, distribution, and reproduction in any medium, provided the original work is properly cited.

\begin{abstract}
Introduction: Acute viral hepatitis is a relatively common infection resulting in hospital attendance after foreign travel. Travellers and doctors are generally aware of hepatitis $A$ and the fact that safe and effective immunisation is available. In contrast, there is no widely available vaccine for hepatitis $E$ and most physicians' experience with this condition is limited. Over the last few years, the number of cases of hepatitis $E$ has increased. Methods: We examined the prevalence of hepatitis $A$ and $E$ among patients presenting to the Hospital for Tropical Diseases between 2000 and 2009. Travel history, demographics and laboratory parameters of these patients were compared. Results: The annual incidence of hepatitis A remained static, while that of hepatitis $E$ increased from 1 to 4. Hepatitis E was associated with older age, travel to the Indian sub-continent (ISC), and visiting friends and relatives (VFR). Peak ALT was similar between patients with hepatitis $A$ or $E$, but as many as a third of those with hepatitis $E$ developed a prolonged INR, compared to $11 \%$ of those with hepatitis A. In addition, patients with hepatitis $E$ had a longer hospital admission by a median of 3 days. Conclusion: Hepatitis $E$ is now the commonest cause of faeco-oral viral hepatitis at this centre, and is associated with laboratory features suggestive of more severe liver damage and longer hospital stay.
\end{abstract}

Keywords: Hepatitis; Returning Traveller

\section{INTRODUCTION}

Hepatitis A and E are both transmitted via the faeco-oral route; both are usually self-limiting but may cause a fulminant hepatitic picture.

There are around 400 cases of hepatitis A reported to the Health Protection Agency (HPA) in the United Kingdom each year. This has fallen dramatically from the peak observed in the late 1980s and early 1990s when there were up to 8000 cases [1]. There is an estimated risk of acquiring hepatitis $\mathrm{A}$ of $0.05 \%$ for each visit to an endemic country [2], most commonly among young adults. The mean incubation period is 28 days. Severity of infection increases with age and fulminant hepatitis is seen in approximately $1 \%$ of cases [1]. Seroprevalence data suggest that most people below the age of 50 in the UK are susceptible. Immunisation is recommended for high-risk groups such as sewage workers and people over the age of five travelling to an endemic country [3]. The vaccine is a formaldehyde inactivated virus with an efficacy around $95 \%$ after two doses [3].

Hepatitis E is also transmitted faeco-orally. Until recently it was thought to be predominately an imported disease. It is most likely a zoonosis originating in pigs [4]. There are four major genotypes (1-4). The HPA reports about 200 cases of hepatitis $E$ each year, with a peak of 326 in 2005 [5]. Approximately 10\% acquired their infection in the UK and were predominantly older men who had direct contact with pigs. The principal genotype in domestic infection is genotype 3, rather than genotypes 1 and 2, which are the most common imported strains. There is no widely available vaccine for hepatitis E although several recent trials have been published [5-7], the most recent of which suggested a vaccine efficacy approaching $100 \%$.

In order to get a better understanding of the prevalence of hepatitis E, we conducted a retrospective analysis of all cases of acute faeco-oral hepatitis among adults presenting to the Hospital for Tropical Diseases (HTD) over 9 years.

\section{METHODS}

All patients seen at the HTD between August 2000 and 
February 2009 who had serologically confirmed diagnoses of hepatitis A or hepatitis E were included. Demographic and travel data were collected prospectively and laboratory and clinical data were collected retrospectively for these cases.

There were 21 cases of hepatitis A diagnosed, (16 admitted, five treated as outpatients). Twenty-two patients with hepatitis E were admitted and seven were treated as outpatients. Twenty were confirmed and two were probable where the IgM for hepatitis E was weakly reactive but the clinical presentation was typical. The year of diagnosis of these patients is shown in Figure 1.

\subsection{Demographics}

Both hepatitis A and hepatitis $\mathrm{E}$ were more common in men (18/29 [62\%] and 15/21 [71\%] respectively). The average age of patients with hepatitis A was 27.9 years (24.6 - 35.5) compared to 34.6 years (29.2 - 47.6) for hepatitis E. (Table 1).

Of the 21 patients with hepatitis A, three were Asian, nine Caucasian, two "other" and seven declined to give this information. Ten were born in Europe, two in South America, two in India, one in Saudi Arabia and six patients declined to give these data.

Nineteen out of 29 (65\%) patients with hepatitis E described themselves as Asian, eight as Caucasian and two declined to give an ethnicity. Eleven were born in the Indian subcontinent, eight in the UK, four in other parts of the world and six declined to give this information.

\subsection{Travel History}

Most patients with hepatitis $\mathrm{E}$ acquired their infection while visiting the Indian sub-continent (ISC): 11 in India, 10 in Bangladesh, three in Pakistan, and two who had extensive travel across SE Asia and the ISC. Only three patients had travelled to other parts of the world (Afghanistan, Latin America, and Sudan). Most patients who acquired hepatitis E (15/29) had travelled to visit family. One patient from the ISC was visiting relatives in the UK when they became unwell; one was a new immigrant from the area; one was a returning UK expatriate; five were holidaymakers; two were working abroad and for four patients the reason for travel was not documented.

In contrast, fewer than half of patients with hepatitis A had travelled to the ISC (four India, one Pakistan, one Sri Lanka). Six had travelled elsewhere (Egypt, Senegal, Madagascar, Colombia, Ghana, and Nigeria). Seven acquired their infection in the UK and travel history was not documented for two (Table 1 and Figure 2). Among patients with hepatitis A four went on holiday; two had visited family; two were teaching abroad; one was a foreign visitor; one a recent immigrant to the UK; one had been studying abroad, and data were not collected in three.
Table 1. Demographic characteristics of patients with hepatitis A and E.

\begin{tabular}{ccc}
\hline & Hepatitis A & Hepatitis E \\
\hline No. of cases & 21 & 29 \\
Male to female ratio & $2.5: 1$ & $1.6: 1$ \\
Age-median (IQR) & $27.9(24.6-35.5)$ & $34.6(29.2-47.6)$ \\
Indian subcontinent (\%) & 30 & $90^{*}$ \\
Visiting friends and relations (\%) & 10 & $55^{*}$ \\
\hline
\end{tabular}

${ }^{*}$ Chi squared $p<0.0001$ (hepatitis A compared with hepatitis E).

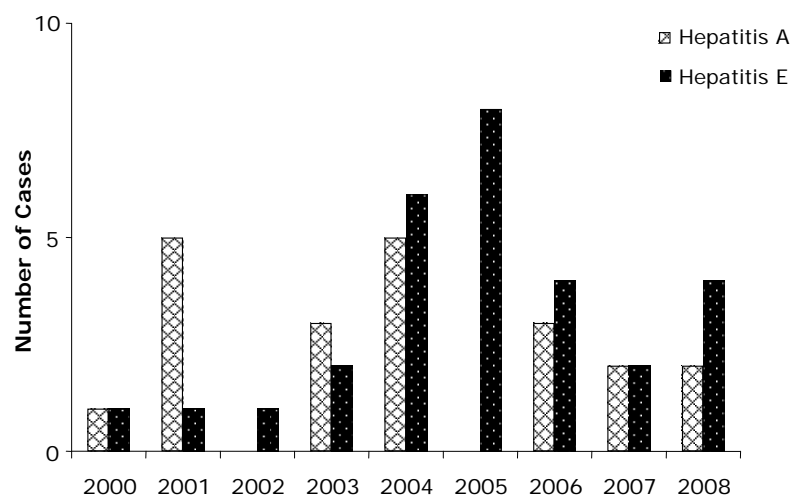

Figure 1. Cases of hepatitis A and E by year of diagnosis.

\subsection{Clinical and Biochemical Data}

The mean length of admission was significantly longer in those with hepatitis E (5.4 days) compared with those with hepatitis A (2.4 days) (Table 2). There was no difference in transaminitis between patients with hepatitis A (ALT mean $2953 \mathrm{IU} / \mathrm{L}$, maximum $6577 \mathrm{IU} / \mathrm{L}$ ) and hepatitis E (ALT mean of $2691 \mathrm{IU} / \mathrm{L}$ and maximum 8887 $\mathrm{IU} / \mathrm{L})$. Jaundice was similar between the two groups (hepatitis A patients had a mean bilirubin $174 \mathrm{IU} / \mathrm{L}$ maximum $737 \mathrm{IU} / \mathrm{L}$, hepatitis $\mathrm{E}$ patients bilirubin mean 187 IU/L maximum 522 IU/L,).

INR was more likely to be prolonged among the patients with hepatitis E (INR greater than 1.2 in 9/26 (35\%) in hepatitis E and 2/19 (10\%) in hepatitis A (Table 2)).

Pregnancy did not appear to be a risk factor; only one patient in this cohort was pregnant and she had hepatitis A. Four patients, all with hepatitis $\mathrm{E}$ had an additional infection: ascaris lumbricoides, mycoplasma, paratyphoid and Strongyloides stercoralis.

\section{DISCUSSION}

Hepatitis E is a non-enveloped spherical RNA virus that is classified as a Hepevirus with four genotypes [8]. The first outbreaks of hepatitis $E$ were recognised in the early 1980s with the virus only identified in 1983 [9]. It is an enterically transmitted virus common in areas with poor 
Table 2. Clinical and biochemical data.

\begin{tabular}{ccc}
\hline & Hepatitis A & Hepatitis E \\
\hline Peak ALT (mean) & 2953 & 2691 \\
Peak bilirubin (mean) & 174 & 187 \\
INR $>1.2^{*}$ & $2 / 19(12)$ & $9 / 26(35)$ \\
Length of Stay if admitted (days) $^{\dagger}$ & 2.4 & 5.4 \\
\hline
\end{tabular}

${ }^{*}$ Chi squared $p<0.0001$ (hepatitis A compared with hepatitis E); ${ }^{\dagger}$ MannWhitney test $p<0.0006$.

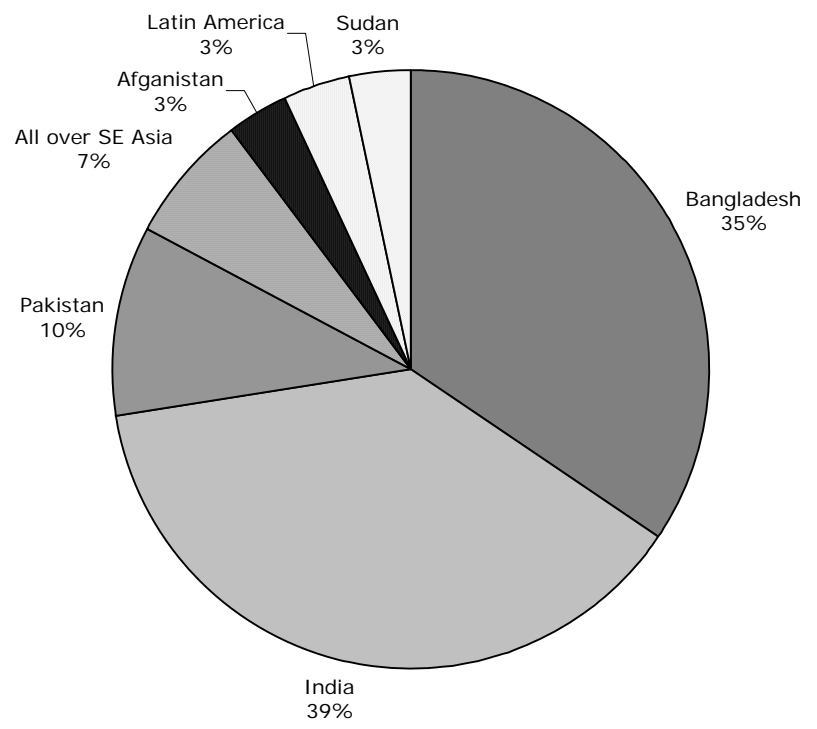

(a)

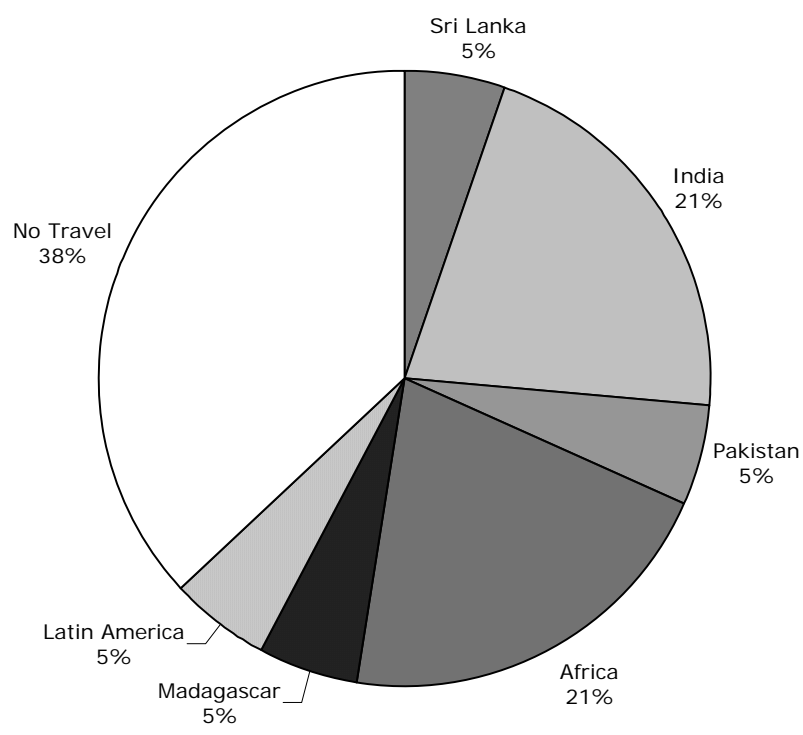

(b)

Figure 2. Country of travel for patients with (a) hepatitis E and (b) hepatitis A.

sanitation, particularly Asia. Outbreaks have also been seen in industrialised countries where pigs are a reservoir and cases are thought to be linked to animal husbandry, although in other cases the source has been difficult to verify [10]. In resource-poor countries, infection is usually acquired in early adult life, which contrasts with hepatitis A that is invariably acquired in childhood. In studies from the UK, infection was more common in older men [11,12]. Hepatitis E is usually a mild, self limiting illness except among pregnant women, immunosuppressed individuals or those with underlying liver disease [6]. However in a series of 17 patients who contracted hepatitis $\mathrm{E}$ in the UK, two developed fulminant liver failure, one of whom required a liver transplant, while the other died [10]. Data from India suggest that pregnant women are more susceptible to severe disease, but the fatality rate was not increased compared to those who were not pregnant [13]. While both hepatitis A and E characteristically produce an acute syndrome, there are reports of chronic infection with hepatitis $\mathrm{E}$ among immunosuppressed people [14-16].

Hepatitis E is increasingly recognised as a common infection. In China, seroprevalence rates are above $40 \%$ [17]. In north India, hepatitis E seroprevalence in children was $28 \%$ [18]. In the UK, $16 \%$ of blood donors in Bristol have serological evidence of exposure to hepatitis E with an increased frequency in older men [10].

In 2005 a study of 329 cases of hepatitis E reported by the HPA found 33 who definitely acquired their infection in the UK and a further 67 who probably did, roughly one-third of the total [19]. Travellers are usually infected with genotypes 1 and 2, whereas infections acquired in this country are usually genotypes 3 or 4 . In this study, none of the patients for who travel data were available acquired hepatitis $\mathrm{E}$ in the UK. This contrasts to at least 7/21 (33\%) of the patients with hepatitis A. This may reflect a sampling bias; symptomatic travellers tend to present to HTD from a catchment area that is predominantly urban and who are likely to have little contact with animals.

Patients who were admitted with hepatitis $\mathrm{E}$ had a longer hospital stay. This may reflect a delay in diagnosis compared to hepatitis A. Once a diagnosis of hepatitis A has been confirmed, clinicians are often prepared to discharge the patient.

Previous infection with hepatitis E appears to confer life-long immunity and a vaccine may soon be widely available. The Walter Reed Army Research Institute recently published the results of a phase 2 study with a recombinant protein vaccine candidate that showed $95.5 \%$ protection [6], while a phase 3 study of a vaccine produced in China showed 100\% efficacy [7]. However, until such time, public health measures including hand hygiene and clean food and water will continue be the primary means of controlling the spread of hepatitis E. 


\section{CONCLUSION}

In recent years hepatitis $\mathrm{E}$ has been seen with increasing frequency at this hospital and it is now more common than hepatitis A. It is most often seen among travellers of Asian descent who go to the ISC to visit family. Whereas previous studies have highlighted the frequency with which pregnant women acquire the infection, this was not the case in this cohort. Physicians should be aware of the increasing morbidity associated with this emerging infectious disease.

\section{ACKNOWLEDGEMENTS}

We are grateful to all staff at the Hospital for Tropical Diseases. Margaret Armstrong is supported by the Special Trustees of the Hospital for Tropical Diseases.

\section{REFERENCES}

[1] Public Health England, "Hepatitis A Laboratory Reports and Statutory Notifications, England and Wales,” 2010. http://www.hpa.org.uk/Topics/InfectiousDiseases/Infectio nsAZ/HepatitisA/EpidemiologicalData/

[2] Behrens, R.H., Collins, M., Botto, B. and Heptonstall, J. (1995) Risk for British travellers of acquiring hepatitis A. British Medical Journal, 311, 193. http://dx.doi.org/10.1136/bmj.311.6998.193a

[3] Public Health England, 2010. http://www.hpa.org.uk/Topics/InfectiousDiseases/Infectio nsAZ/HepatitisA/Guidelines/

[4] Li, L., Zhu, Y., Fu, H., Wei, X., Wang, L., Liang, J., Ji, Y., Tang, R. and Zhuang, H. (2009) Full-genome nucleotide sequence and analysis of a Chinese swine hepatitis $\mathrm{E}$ virus isolate of genotype 4 identified in the Guangxi Zhuang autonomous region: Evidence of zoonotic risk from swine to human in South China. Liver International, 29, 1230-1240. http://dx.doi.org/10.1111/j.1478-3231.2009.02012.x

[5] Public Health England, 2010. http://www.hpa.org.uk/Topics/InfectiousDiseases/Infectio nsAZ/HepatitisE/Surveillance/

[6] Shrestha, M.P., Scott, R.M., Joshi, D.M., Mammen, P.M., Thapa, G.B., Thapa, N., et al. (2007) Safety and efficacy of a recombinant hepatitis E vaccine. The New England Journal of Medicine, 356, 895-903. http://dx.doi.org/10.1056/NEJMoa061847

[7] Zhu, F.C., Zhang, J., Zhang, X.F., Zhou, C., Wang, Z.Z., Huang, S.J., Wang, H., et al. (2010) Efficacy and safety of a recombinant hepatitis $E$ vaccine in healthy adults: A large-scale, randomised, double-blind placebo-controlled, phase 3 trial. Lancet, 376, 895-902. http://dx.doi.org/10.1016/S0140-6736(10)61030-6

[8] Mushahwar, I.K. (2008) Hepatitis E virus: molecular virology, clinical features, diagnosis, transmission, epidemiology, and prevention. Journal of Medical Virology,
80, 646-658. http://dx.doi.org/10.1002/jmv.21116

[9] Krawczynski, K. (2007) Hepatitis E vaccine-Ready for prime time? The New England Journal of Medicine, 356, 949-951. http://dx.doi.org/10.1056/NEJMe068311

[10] Ijaz, S., Arnold, E., Banks, M., Hewitt, K., Ngui, S.L., Boxall, E., et al. (2005) Non-travel-associated hepatitis E in England and Wales: Demographic, clinical, and molecular epidemiological characteristics. The Journal of Infectious Diseases, 192, 1166-1172. http://dx.doi.org/10.1086/444396

[11] Dalton, H.R., Thurairajah, P.H., Fellows, H.J., Hussaini, H.S., Mitchell, J., Bendall, R., et al. (2007) Autochthonous hepatitis E in southwest England. Journal of Viral Hepatitis, 14, 304-309. http://dx.doi.org/10.1111/j.1365-2893.2006.00800.x

[12] De Silva, A.N., Muddu, A.K., Iredale, J.P., Sheron, N., Khakoo, S.I. and Pelosi, E. (2008) Unexpectedly high incidence of indigenous acute hepatitis $\mathrm{E}$ within South Hampshire: Time for routine testing? Journal of Medical Virology, 80, 283-288. http://dx.doi.org/10.1002/jmv.21062

[13] Bhatia, V., Singhal, A., Panda, S.K. and Acharya, S.K. (2008) A 20-year single-center experience with acute liver failure during pregnancy: Is the prognosis really worse? Hepatology, 48, 1577-1585. http://dx.doi.org/10.1002/hep.22493

[14] Dalton, H.R., Bendall, R.P., Keane, F.E., Tedder, R.S. and Ijaz, S. (2009) Persistent carriage of hepatitis E virus in patients with HIV infection. The New England Journal of Medicine, 361, 1025-1027. http://dx.doi.org/10.1056/NEJMc0903778

[15] Haagsma, E.B., Niesters, H.G., van den Berg, A.P., Riezebos-Brilman, A., Porte, R.J., Vennema, H., et al. (2009) Prevalence of hepatitis E virus infection in liver transplant recipients. Liver Transplantation, 15, 12251258.

[16] Haagsma, E.B., van den Berg, A.P., Porte, R.J., Benne, C.A., Vennema, H., Reimerink, J.H., et al. (2008) Chronic hepatitis $\mathrm{E}$ virus infection in liver transplant recipients. Liver Transplantation, 14, 547-553. http://dx.doi.org/10.1002/lt.21480

[17] Li, R.C., Ge, S.X., Li, Y.P., Zheng, Y.J., Nong, Y., Guo, Q.S., et al. (2006) Seroprevalence of hepatitis E virus infection, rural southern People's Republic of China. Emerging Infectious Diseases Journal, 12, 1682-1688. http://dx.doi.org/10.3201/eid1211.060332

[18] Mohanavalli, B., Dhevahi, E., Menon, T., Malathi, S. and Thyagarajan, S.P. (2003) Prevalence of antibodies to hepatitis A and hepatitis E virus in urban school children in Chennai 1. Indian Pediatrics, 40, 328-331.

[19] Lewis, H.C., Boisson, S., Ijaz, S., Hewitt, K., Ngui, S.L., Boxall, E., et al. (2008) Hepatitis E in England and Wales. Emerging Infectious Diseases Journal, 14, 165-167. http://dx.doi.org/10.3201/eid1401.070307 